\title{
Relationship Between Balance Recovery From a Forward Fall and Lower-Limb Rate of Torque Development
}

\section{AUTHOR(S):}

Ochi, Akira; Ohko, Hiroshi; Hayashi, Takahiro; Osawa, Tatsuya; Sugiyama, Yuto; Nakamura, Shota; Ibuki, Satoko; Ichihashi, Noriaki

\section{CITATION:}

Ochi, Akira ...[et al]. Relationship Between Balance Recovery From a Forward Fall and Lower-Limb Rate of Torque Development. Journal of Motor Behavior 2020, 52(1): 71-78

\section{ISSUE DATE:}

2020

URL:

http://hdl.handle.net/2433/265271

\section{RIGHT:}

This is an Accepted Manuscript of an article published by Taylor \& Francis in 'Journal of Motor Behavior' on 27 March. 2019 (published online), available online: https://doi.org/10.1080/00222895.2019.1585743; The full-text file will be made open to the public on 27 March 2020 in accordance with publisher's 'Terms and Conditions for Self-Archiving'; This is not the published version. Please cite only the published version. この論文は出版蝂でありません。引用の際には出 版社版をご確認ざ利用ください。 
Title Page

Type of submission: Research article

Title:

\section{Relationship between balance recovery from a forward fall and lower-limb rate of} torque development

Running head: Balance recovery and rate of torque development

Akira Ochi ${ }^{\text {a }}$, Hiroshi Ohko ${ }^{\text {a }}$, Takahiro Hayashi ${ }^{a}$, Tatsuya Osawa ${ }^{b}$, Yuto Sugiyama ${ }^{c}$, Shota Nakamura ${ }^{d}$, Satoko Ibuki ${ }^{\text {e }}$, Noriaki Ichihashi ${ }^{\text {e }}$

a. Division of Physical Therapy, Faculty of Care and Rehabilitation, Seijoh University: 2-172 Fukinodai, Toukai-City, Aichi 476-8588, Japan

b. Faculty of Rehabilitation, Ichinomiyanishi Hospital: 1, Kaimei, Ichinomiya-City, Aichi 494-0001, Japan

c. Faculty of Rehabilitation, Kakamigahara Rehabilitation Hospital: 6-8-2, Unumayamazakicho, Kakamigahara-City, Gifu 509-0124, Japan

d. Faculty of Rehabilitation, Yamada Hospital: 7-101, Terada, Gifu-City, Gifu 5010104, Japan.

e. Department of Physical Therapy, Human Health Sciences, Graduate School of Medicine, Kyoto University: 53, Kawahara-cho, Shogoin, Sakyo-ku, Kyoto 6068507, Japan

\section{Corresponding Author:}

\section{Akira Ochi}

ORCiD ID: https://orcid.org/0000-0003-2754-7383

Division of Physical Therapy, Faculty of Care and Rehabilitation, Seijoh University: 2172 Fukinodai, Toukai-City, Aichi 476-8588, Japan

Tel: $+81-52-601-6986$ (direct line)

Fax: +81-52-601-6245

Email: ochi@seijoh-u.ac.jp 
40

41

\section{Abstract}

The authors examined the relationship between the maximum recoverable lean angle via the tether-release method with early- or late-phase rate of torque development (RTD) and maximum torque of lower-limb muscle groups in 56 young healthy adults. Maximal isometric torque and RTD at the hip, knee, and ankle were recorded. The RTD at 50-ms intervals up to $250 \mathrm{~ms}$ from force onset was calculated. The results of a stepwise multiple regression analysis, early RTD for hip flexion, and knee flexion were chosen as predictive variables for the maximum recoverable lean angle. The present study suggests that some of the early RTD in the lower limb muscles, but not the maximum isometric torque, can predict the maximum recoverable lean angle.

Key words: Balance recovery; Rate of torque development; Maximum isometric torque; Maximum recoverable lean angle 
The ability to step forward rapidly with the lower limb plays an important role in preventing a fall after forward loss of balance (Van Dieën, Pijnappels, \& Bobbert, 2005). In the tether-release method, which is used to investigate step recovery in fall avoidance, the subject is placed in a forward inclined position with hips pulled backwards (HsiaoWecksler, 2008). Individuals who can recover their balance in a single step from a maximum initial forward leaning position, known as the maximum recoverable lean angle, have a better ability to recover balance (Thelen, Wojcik, Schultz, Ashton-Miller, \& Alexander, 1997). Several previous studies using the tether-release method revealed that older adults have less maximum recoverable lean angle compared to young individuals (Hsiao-Wecksler \& Robinovitch, 2007; Madigan \& Lloyd, 2005; Thelen et al., 1997; Wojcik, Thelen, Schultz, Ashton-Miller, \& Alexander, 1999). Additionally, older adults are more likely to use multiple steps to recover balance as the initial forward lean angle increases (Carty et al., 2015; Carty, Barrett, et al., 2012; Carty, Cronin, Lichtwark, Mills, $\&$ Barrett, 2012). In older adults, the use of multiple steps to recover balance during tetherrelease experiments is a predictor of future fall events (Carty et al., 2015).

Several studies have attempted to predict the maximum recoverable lean angle or magnitude using the maximum joint torque of the lower limb. In a study of young and older adults, isometric torques of hip flexion and ankle plantarflexion were not good predictors of maximum recoverable lean angle (Wojcik, Thelen, Schultz, Ashton-Miller, \& Alexander, 2001). In contrast, other studies showed that the maximal isometric joint 
torques of ankle plantarflexion and knee extension could predict the margin of stability in young and older adults (Karamanidis, Arampatzis, \& Mademli, 2008). Furthermore, ankle dorsiflexion torque is also a weak predictor of balance recovery in older adults (Grabiner, Owings, \& Pavol, 2005). In a recent study (Graham, Carty, Lloyd, \& Barrett, 2015) amongst community-dwelling older adults, which used a stepwise multiple regression to analyze maximal recoverable lean magnitude as the independent variable, some joint moments and powers in the stepping leg during balance recovery were extracted as explanatory variables, whereas isometric joint torques were not. These studies have all measured maximum joint torques of the lower limb using an isokinetic dynamometer. Thus, it is not clear if maximum joint torques is a good predictor of maximum recoverable lean angle. Balance recovery requires the timely generation of appropriate joint moment and muscle power to step forward quickly (Aragão, Karamanidis, Vaz, \& Arampatzis, 2011; Arampatzis, Peper, \& Bierbaum, 2011; Madigan, 2006); thus, apart from muscle strength, explosive force was also thought to be necessary for rapid stepping.

The relationship between the maximum recoverable lean angle and maximum isometric torque of the lower limb has been frequently investigated, whereas the rate of torque development (RTD), which is the rate at which torque production occurs, has not been investigated. The characteristics of RTD are inconsistent during contraction. A relatively early-phase RTD within the first $100 \mathrm{~ms}$ of a rapid contraction shows great variability between different individuals (Folland, Buckthorpe, \& Hannah, 2014), while a late-phase RTD of a longer duration (100-250 ms) has a strong correlation with maximum muscle strength (Andersen \& Aagaard, 2006). The early phase of RTD is related to 
neuronal factors like individual motor unit discharge rate. Since this is the chief forcegenerating capacity in an explosive situation, it likely plays an important role in fall avoidance (Maffiuletti et al., 2016).

The aim of this pilot study was to investigate the correlation between the maximum recoverable lean angle, using the tether-release method with maximum torque, and RTD in each phase and each joint of the stepping limb. Fall avoidance relies on production of adequate voluntary muscle strength in a short period of time. In addition, achieving balance recovery from a larger initial lean angle requires faster joint velocity (Madigan \& Lloyd, 2005) and greater muscular activity (Thelen et al., 2000). We hypothesized that early RTD will be a better predictor of maximum recoverable lean angle than late RTD or maximum isometric torque of the lower limbs.

\section{1. Participants}

The participants comprised 56 untrained healthy young adults (28 men; mean age, $21.0 \pm 0.8$ years; height, $1.70 \pm 0.05$; weight, $62.1 \pm 7.2 \mathrm{~kg} ; 28$ women; mean age, $21.1 \pm$ 0.8 years; height, $1.55 \pm 0.06$; weight, $49.0 \pm 4.7 \mathrm{~kg}$ ). People with orthopedic disorders that would impede fall-avoidance stepping performance were excluded. Furthermore, targeted participants were free of upper and lower limb pain and discomfort. G*Power (ver. 3.1.9.2) was used to determine the sample size. To calculate the sample size of a multiple regression analysis, we used Cohen's $\mathrm{f}^{2}$ for effect size, set at 0.35 (representing 
120

121

122

123

124

a large effect) and at an alpha level of 0.05 and power of 0.80 . The number of predictors was set at 30, as RTD consists of 6 joint movements and 5 time points. Based on the above assumptions, a minimum of 36 participants were required for this study. The study was approved by the Seijoh University Ethics Committee (Approval Number: 16PT07) and informed consent was obtained from all participants who received sufficient explanation about the research objectives and methods.

\section{2. Experimental procedures}

2. 2. 1. Measurements of maximum recoverable lean angle Participants were fitted with a harness (Full harness EHC-9A, Sanko, Inc., Japan) and a tether was attached at the posterior lumbar L1-L2 level. The tether release switch, a customized car seatbelt buckle, was fixed to a metal strut that permitted height adjustment behind the subject. While tethered, with arms folded the chest, the participants adopted a forward inclined ready-position with legs placed horizontally and shoulder-width apart. A Chapman dominant leg test (Chapman, Chapman, \& Allen, 1987) was performed, and the leg that used for stepping during the fall was defined as the dominant or stepping leg. Participants were instructed in advance to use their dominant leg during the stepping movement. Reflective markers were attached to the acromion and lateral malleolus on the stepping-leg side. An optical, high-speed camera synchronized to a personal computer was installed at a position $2 \mathrm{~m}$ lateral to the stepping-leg side. The camera frame rate was 240 fps. Participants were instructed to keep their back straight in the forward inclined position prior to tether release. The forward inclination angle (Hsiao-Wecksler \& Robinovitch, 
142

143

144

145

2007) between the axis perpendicular to the floor and the line connecting the acromion and lateral malleolus markers on the stepping-leg side was derived using a free imaging analysis software (ImageJ, version 1.44). For safety, a cushioned mat was placed $2 \mathrm{~m}$ in front of the subject.

Participants were instructed to quickly move their stepping leg forward at the instant the tether was released and limit this movement to 1 step. Forward inclination angle was increased by $5^{\circ}$ increments starting from $15^{\circ}$ until single-step balance recovery was no longer possible, or a portion of their body touched the cushioned mat in front of them. After failing twice in the single step balance recovery, the forward inclination angle was then reduced by $2^{\circ}$ increments until balance recovery was again successful twice, which was defined as the maximum recoverable lean angle.

\section{2. 2. Torque measurements}

A hand-held dynamometry (HHD) (Mobie MT-100, SAKAImed, Japan) and pull sensor (MT-150, SAKAImed, Japan) were used for torque measurements of flexion and extension in the hip, knee, and ankle (Fig. 1). The device senses and measures force by pulling a distortion gauge, and joint torque can be measured with a fixation to the nonelastic belt (Suzuki, 2015). Hence, the HHD with external fixation was used in this study so that the examiner is not required to hold the HHD. The lower limb of the stepping side during balance recovery tasks (i.e., dominant leg) was measured. The positions of the joints for each of the force measurements by the HHD are shown in Fig. 1. Limb position and the belt with pull sensor installation locations (i.e., points of resistance) were based 
164

165

166

on the methods of Thorborg et al. (2013), Koblbauer et al. (2011), and Moraux et al. (2013) for measurements involving the hip, knee, and ankle dorsiflexion, respectively. The participants were seated on a plinth adjustable to their height in an upright position and their hips and knees were positioned at approximate right angles. The joint angles were measured with a goniometer based on the body landmark (e.g., line connecting the greater trochanter, knee joint center, lateral malleolus) in the testing positions. The belt with pull sensor was positioned distally on the thigh, distally on the anterior aspect of the tibia, distally on the posterior calf complex, and on top of the foot at the level of the metatarsal, for hip flexion, knee extension, knee flexion, and ankle dorsiflexion, respectively. For hip extension, the belt was positioned at the posterior calf-complex with participants in a prone position. Ankle plantarflexion torque had to be measured with knee extension, because the stepping reaction from a forward fall required a push-off in the knee extension position. Specifically, for ankle plantarflexion, the participants were positioned directly on an isokinetic joint torque measuring device in a long sitting position with hips flexed at $70^{\circ}$, knees extended at $0^{\circ}$, trunk and thighs fixed, and the belt with pull sensor installed between the planta and the ankle plate. To ensure muscular contraction without joint movement, the belt with the pull sensor was tautened to keep the limb in the torque measurements position. The length of the lever arm, which spanned the distance between the center of the joint and the point of effort, i.e., the location of the belt with pull sensor, was recorded for each subject in all measurements. A previous study has reported that the rate of force development measured using the HHD has a high reliability (Mentiplay et al., 2015). 
moderate effort before measurement. To calculate the isometric maximum joint torque and

RTD of these joint movements, participants were instructed to quickly exert maximum successively measured three times.

\section{3. Data analyses}

Force data were band-pass filtered at $20-500 \mathrm{~Hz}$ with second-order Butterworth torque-time curve peak values $(\mathrm{Nm} / \mathrm{kg})$. The average value of three maximal joint torque was adopted used for the final analyses.

The time of torque onset was defined as the moment when the HHD reading exceeded three standard deviations (SD) below the average value during the $500 \mathrm{~ms}$ before force exertion, based on the methods of de Ruiter, Kooistra, Paalman, and de Haan (2004). 
208

209

curve was calculated $(\mathrm{Nm} / \mathrm{kg} / \mathrm{s})$ from onset with every $50 \mathrm{~ms}$ interval up to $250 \mathrm{~ms}$, named $\mathrm{RTD}_{0-50}, \mathrm{RTD}_{0-100}, \mathrm{RTD}_{0-150}, \mathrm{RTD}_{0-200}$, and $\mathrm{RTD}_{0-250}$. The average value of three RTDs for each time point was used for the final analyses.

\section{4. Statistical processing}

The normality of all data was examined with the Shapiro-Wilk test. All data, including the maximum joint torques, each time point of RTD, and the maximum recoverable lean angle, were normally distributed. The intra-rater reliability of the maximum joint torque and RTD at each time point among three measurements was estimated using intra-class correlation coefficients (ICC). Pearson's product moment correlations assessed the relationships between maximum recoverable lean angle and each time point on RTD-dependent variables. The Pearson product moment correlations were presented for all RTD at each time point and maximum joint torque, and multicollinearity was verified prior to multiple regression analyses. If the correlation coefficient between the two RTD in the same joint movement exceeded 0.80 , the later RTD was excluded from the explanatory variables. Multiple stepwise regression analyses were performed using maximum recoverable lean angle as the independent variable and lower-limb maximum joint torque and each time point on RTD as explanatory variables. The statistical significance threshold was set at $5 \%$. 
joint movement. Additionally, the ICCs for the RTD at each time point and among targeted

232 joint movements are provided in Table 1 . Although early RTD ( $\geq 100 \mathrm{~ms}$ ) for some joint 233 movements exhibited a lower value compared with late RTD, these ICC results indicated 234 substantial to almost perfect reliability (Landis \& Koch, 1977). with hip flexion $\left(r=0.561\right.$, Cohen's $\left.\mathrm{f}^{2}=0.46\right)$, hip extension $\left(r=0.301\right.$, Cohen's $\left.\mathrm{f}^{2}=0.10\right)$, knee flexion $\left(r=0.341\right.$, Cohen's $\left.\mathrm{f}^{2}=0.13\right)$, ankle plantarflexion $\left(r=0.334\right.$, Cohen's $\mathrm{f}^{2}=$ $0.13)$, and ankle dorsiflexion $\left(r=0.538\right.$, Cohen's $\left.\mathrm{f}^{2}=0.41\right)$ by maximum joint torque. As shown in Table 3, a significant positive correlation was observed for RTD of each time point on several of these. All the hip flexion RTDs at each time point showed a significant relationship, while significant relationships were not found for all the knee extension RTDs at each time point. 
correlation coefficient of more than 0.80 . This means that the maximum torque and $\mathrm{RTD}_{0}$ 200 and $\mathrm{RTD}_{0-250}$ were strongly correlated. Therefore, $\mathrm{RTD}_{0-200}$ and $\mathrm{RTD}_{0-250}$ were excluded from the explanatory variables to avoid multicollinearity. Instead, the maximum joint torque was included. Multiple stepwise regression analysis showed that hip flexion $\mathrm{RTD}_{0-50}$, knee flexion $\mathrm{RTD}_{0-100}$, and hip flexion $\mathrm{RTD}_{0-150}$ (adjusted $^{2}=0.589$, $\mathrm{F}=27.27, \mathrm{p}<0.001)$ were the best predictors of maximum recoverable lean angle (Table 4).

\section{+++++ Include Table 4 here +++++}

\section{Discussion}

To the best of our knowledge, this is the first study to examine the relationship between the maximum recoverable lean angle created by the tether-release method and RTD for the lower limb. Our results support our hypothesis that early-phase RTD predicts the maximum recoverable lean angle better than maximum isometric torque. Maximum recoverable lean angle was correlated with maximum isometric torque and RTD for some joint movements, but not knee extension in the single regression analysis. A stepwise multiple regression analysis involving RTD less than $200 \mathrm{~ms}$ and maximal joint torque showed that hip flexion $\operatorname{RTD}_{0-50}$ and $\mathrm{RTD}_{0-150}$ as well as knee flexion $\mathrm{RTD}_{0-100}$ were predictors of maximum recoverable lean angle, as opposed to maximum isometric torque. Additionally, the standard partial regression coefficient displayed a stronger effect in the 
274

275

RTD $_{0-50}$ and $\mathrm{RTD}_{0-100}$ of the hip and knee flexion than the $\mathrm{RTD}_{0-150}$ of hip flexion.

Single regression analysis showed that the maximum isometric torque, excluding knee extension, significantly correlated with maximum recoverable lean angle. The effect of maximum muscle strength on RTD increases with time from the onset of contraction; particularly as $\mathrm{RTD}_{0-200}$ has a strong correlation with maximum muscle strength (Andersen \& Aagaard, 2006). This may explain our results indicating that the maximum isometric torque, excluding knee extension, and $\mathrm{RTD}_{0-200}$ and $\mathrm{RTD}_{0-250}$ in the same joint movement were both significantly correlated with the maximum recoverable lean angle. Although there were significant positive correlations in most of the joint movements, none were chosen as predictors of maximum isometric joint torque in the stepwise multiple regression analysis. Maximum available torques in the stepping leg were not used during the balance recovery from tether-release in younger adults (Graham, Carty, Lloyd, Lichtwark, \& Barrett, 2014; Wojcik et al., 2001). Therefore, as an individual's maximum torque level does not directly relate to the balance recovery capacity, isometric maximum joint torque is only at most a moderate predictor of maximum recoverable lean angle.

Reduced postural stability during upright standing in older adults is related to decreased leg extension rate of force development (Izquierdo, Aguado, Gonzalez, López, \& Häkkinen, 1999). Decreased production of explosive force might affect the time until neuromuscular response during balance recovery. The muscle reaction time for the stepping limb in tether release was within $80 \mathrm{~ms}$ (Thelen et al., 2000). Therefore, early RTD of lower limb joint torque is likely involved in impulsive situations such as fall avoidance. In fact, early RTD, namely the $\mathrm{RTD}_{0-50}$ of hip flexion and the $\mathrm{RTD}_{0-100}$ of knee 
flexion, were extracted as predictors of the maximum recoverable lean angle in this study.

It has been reported that early RTD is predominantly dependent on muscular activation

levels at the onset of the contraction (de Ruiter et al., 2004). Recruiting a larger proportion

of the available motor units is required to achieve a large and rapid stepping movement

during balance recovery (Cronin, Barrett, Lichtwark, Mills, \& Carty, 2013). The lower

rate of development for muscle activation has been shown to lead to decreased rate of

302 force generation in the lower leg, resulting in an inadequate recovery response and

flexion torques, chosen as predictive variables in the current study, work in

the early phase during the tether release step, and contribute to forward progression and knee flexion in the stepping limb (Madigan, 2006). The rate of

hip flexion moment generation during balance recovery is related to the maximum recoverable lean angle magnitude for tether-release (Arampatzis et al., 2011). Another study also reported that the semitendinosus peak muscular activity contributing to knee flexion was significantly associated with step the balance recovery capacity and the lower limb early RTD in the current study may be indirectly related to the ability to execute large and rapid steps.

In a previous study of lower limb torques measured by an isokinetic dynamometer and a simple linear regression analysis of balance recovery, the margin of stability for joint torques of the ankle plantarflexion and knee extension were predicted as $44 \%$ and $35 \%$, respectively (Karamanidis et al., 2008), and ankle dorsiflexion torque predicted 
maximum recoverable lean angle in older adults at a rate of $30 \%$ (Grabiner et al., 2005).

Moreover, ankle plantarflexion and hip flexion muscle strength predicted the maximum recoverable lean magnitude at contribution rates of $18 \%$ and $19 \%$, respectively (Graham et al., 2015). Although this study of healthy young volunteers differs from the studies that included older adults, the $\mathrm{RTD}_{0-50}$ of hip flexion and $\mathrm{RTD}_{0-100}$ of knee flexion, and the RTD $_{0-150}$ of hip flexion that were measured by a HHD predicted the maximum recoverable lean angle at a multiple coefficient of determination of 59\%. The comprehensive analysis including maximum isometric torque of the lower limbs and RTD in this study demonstrated that maximum recoverable lean angle can be predicted. The relationship between explosive force and maximum recoverable lean angle, including kinematic analysis of older adults, needs to be investigated in the future.

When interpreting the results of the present study, caution is needed regarding the following limitations. First, since the joint angles at peak contraction was not confirmed, participants may have been allowed a slight movement of the joint during the explosive maximum torque measurement, with the exception of ankle plantarflexion. Participants kept the limb position with the HHD belt taut at the position in which maximum torque was produced. This could cause slight muscular activation, which might have affected maximum joint torque. Nevertheless, the RTD at each time point and each joint had moderate to high reproducibility even if there are limitations of the method used for joint torque measurements in the current study. Second, the joint torque measurements used were isometric contractions and do not reflect the joint angular speed pertinent to balance recovery stepping. Third, although there may be a gender difference in magnitude of joint 
340 torques used for balance recovery stepping (Wojcik et al., 2001), the regression analysis 341 in the current study included men and women. Lastly, as no kinesiologic or 342 electromyographic analysis of the tether-release method was conducted, it remains unclear 343 how the participants' joint strength contributed, or how muscle co-activations or 344 coordination of contraction timing may have affected balance recovery. Forward balance 345 loss recovery was accomplished by adequate trunk regulation, lower limb moment 346 generation, power, and a long and rapid step (Graham et al., 2015). Accordingly, we agree 347 that predictor variables for maximum recoverable lean angle, including kinematic analysis 348 of tether release stepping must be determined. In particular, it is necessary to clarify the explosive force of lower limbs that contributes to the expansion of the step length from the maximum recoverable lean angle. $\mathrm{RTD}_{0-100}$ were related to $59 \%$ of the shared variance of maximum recoverable lean angle. in healthy young adults. 
362 None of the authors report a conflict of interest.

363

$364 \quad$ Funding

365 This research did not receive any specific grant from funding agencies in the public,

366 commercial, or not-for-profit sectors.

367

368

369 


\section{References}

Andersen, L. L., \& Aagaard, P. (2006). Influence of maximal muscle strength and intrinsic muscle contractile properties on contractile rate of force development. European Journal of Applied Physiology, 96(1), 46-52. https://doi.org/10.1007/s00421-005-0070-z

Aragão, F. A., Karamanidis, K., Vaz, M. A., \& Arampatzis, A. (2011). Mini-trampoline exercise related to mechanisms of dynamic stability improves the ability to regain balance in elderly. Journal of Electromyography and Kinesiology, 21(3), 512-518. https://doi.org/10.1016/j.jelekin.2011.01.003

Arampatzis, A., Peper, A., \& Bierbaum, S. (2011). Exercise of mechanisms for dynamic stability control increases stability performance in the elderly. Journal of Biomechanics, 44(1), 52-58. https://doi.org/10.1016/j.jbiomech.2010.08.023

Carty, C. P., Barrett, R. S., Cronin, N. J., Lichtwark, G. A., Mills, P. M., \& Ferrucci, L. (2012). Lower limb muscle weakness predicts use of a multiple-versus single-step strategy to recover from forward loss of balance in older adults. Journals of Gerontology - Series A Biological Sciences and Medical Sciences, 67(11), 1246-1252. https://doi.org/10.1093/gerona/gls149

Carty, C. P., Cronin, N. J., Lichtwark, G. A., Mills, P. M., \& Barrett, R. S. (2012). Lower limb muscle moments and power during recovery from forward loss of balance in male and female single and multiple steppers. Clinical Biomechanics (Bristol, Avon), 27(10), 1031-7. https://doi.org/10.1016/j.clinbiomech.2012.07.009

Carty, C. P., Cronin, N. J., Nicholson, D., Lichtwark, G. A., Mills, P. M., Kerr, G., ... Barrett, R. S. (2015). Reactive stepping behaviour in response to forward loss of balance predicts future falls in community-dwelling older adults. Age and Ageing, 44(1), 109-115. https://doi.org/10.1093/ageing/afu054 
Chapman, J. P., Chapman, L. J., \& Allen, J. J. (1987). The measurement of foot preference. Neuropsychologia, 25(3), 579-584. https://doi.org/10.1016/0028-3932(87)90082-0

Cronin, N. J., Barrett, R. S., Lichtwark, G., Mills, P. M., \& Carty, C. P. (2013). Decreased lower limb muscle recruitment contributes to the inability of older adults to recover with a single step following a forward loss of balance. Journal of Electromyography and Kinesiology, 23(5), 1139-1144. https://doi.org/10.1016/j.jelekin.2013.05.012

de Ruiter, C. J., Kooistra, R. D., Paalman, M. I., \& de Haan, A. (2004). Initial phase of maximal voluntary and electrically stimulated knee extension torque development at different knee angles. Journal of Applied Physiology, 97(5), 1693-1701. https://doi.org/10.1152/japplphysiol.00230.2004

Folland, J. P., Buckthorpe, M. W., \& Hannah, R. (2014). Human capacity for explosive force production: neural and contractile determinants. Scandinavian Journal of Medicine \& Science in Sports, 24(6), 894-906. https://doi.org/10.1111/sms.12131

Grabiner, M. D., Owings, T. M., \& Pavol, M. J. (2005). Lower extremity strength plays only a small role in determining the maximum recoverable lean angle in older adults. The Journals of Gerontology. Series A, Biological Sciences and Medical Sciences, 60(11), 1447-1450. https://doi.org/60/11/1447 [pii]

Graham, D. F., Carty, C. P., Lloyd, D. G., \& Barrett, R. S. (2015). Biomechanical predictors of maximal balance recovery performance amongst community-dwelling older adults. Experimental Gerontology, 66, 39-46. https://doi.org/10.1016/j.exger.2015.04.006

Graham, D. F., Carty, C. P., Lloyd, D. G., Lichtwark, G. A., \& Barrett, R. S. (2014). Muscle contributions to recovery from forward loss of balance by stepping. Journal of Biomechanics, 47(3), 667-674. https://doi.org/10.1016/j.jbiomech.2013.11.047

Hsiao-Wecksler, E. T. (2008). Biomechanical and age-related differences in balance recovery using the tether-release method. Journal of Electromyography and Kinesiology, 18(2), 
179-187. https://doi.org/10.1016/j.jelekin.2007.06.007

Hsiao-Wecksler, E. T., \& Robinovitch, S. N. (2007). The effect of step length on young and elderly women's ability to recover balance. Clinical Biomechanics, 22(5), 574-580. https://doi.org/10.1016/j.clinbiomech.2007.01.013

Izquierdo, M., Aguado, X., Gonzalez, R., López, J. L., \& Häkkinen, K. (1999). Maximal and explosive force production capacity and balance performance in men of different ages. European Journal of Applied Physiology and Occupational Physiology, 79(3), 260-7. https://doi.org/10.1007/s004210050504

Karamanidis, K., Arampatzis, A., \& Mademli, L. (2008). Age-related deficit in dynamic stability control after forward falls is affected by muscle strength and tendon stiffness. Journal of Electromyography and Kinesiology, 18(6), 980-989. https://doi.org/10.1016/j.jelekin.2007.04.003

Koblbauer, I. F., Lambrecht, Y., van der Hulst, M. L., Neeter, C., Engelbert, R. H., Poolman, R. W., \& Scholtes, V. A. (2011). Reliability of maximal isometric knee strength testing with modified hand-held dynamometry in patients awaiting total knee arthroplasty: useful in research and individual patient settings? A reliability study. $B M C$ Musculoskeletal Disorders, 12(1), 249. https://doi.org/10.1186/1471-2474-12-249

Landis, J. R., \& Koch, G. G. (1977). The measurement of observer agreement for categorical data. Biometrics, 33(1), 159-74. https://doi.org/10.2307/2529310

Madigan, M. L. (2006). Age-related differences in muscle power during single-step balance recovery. Journal of Applied Biomechanics, 22(3), 186-93. Retrieved from http://www.ncbi.nlm.nih.gov/pubmed/17215550

Madigan, M. L., \& Lloyd, E. M. (2005). Age and stepping limb performance differences during a single-step recovery from a forward fall. The Journals of Gerontology. Series A, Biological Sciences and Medical Sciences, 60(4), 481-5. Retrieved from 
http://www.ncbi.nlm.nih.gov/pubmed/15933388

Maffiuletti, N. A., Aagaard, P., Blazevich, A. J., Folland, J., Tillin, N., \& Duchateau, J.

(2016). Rate of force development: physiological and methodological considerations.

European Journal of Applied Physiology, 116(6), 1091-116.

https://doi.org/10.1007/s00421-016-3346-6

Mentiplay, B. F., Perraton, L. G., Bower, K. J., Adair, B., Pua, Y. H., Williams, G. P., ... Clark, R. A. (2015). Assessment of lower limb muscle strength and power using handheld and fixed dynamometry: A reliability and validity study. PLoS ONE, 10(10), 1-18. https://doi.org/10.1371/journal.pone.0140822

Moraux, A., Canal, A., Ollivier, G., Ledoux, I., Doppler, V., Payan, C., \& Hogrel, J. Y. (2013). Ankle dorsi- and plantar-flexion torques measured by dynamometry in healthy subjects from 5 to 80 years. BMC Musculoskeletal Disorders, 14(1), 104. https://doi.org/10.1186/1471-2474-14-104

Pijnappels, M., Bobbert, M. F., \& Van Dieën, J. H. (2005). Control of support limb muscles in recovery after tripping in young and older subjects. Experimental Brain Research, 160(3), 326-33. https://doi.org/10.1007/s00221-004-2014-y

Suzuki, T. (2015). Reliability of measurements of knee extensor muscle strength using a pulltype hand-held dynamometer. Journal of Physical Therapy Science, 27(3), 967-71. https://doi.org/10.1589/jpts.27.967

Thelen, D. G., Muriuki, M., James, J., Schultz, A. B., Ashton-Miller, J. A., \& Alexander, N. B. (2000). Muscle activities used by young and old adults when stepping to regain balance during a forward fall. Journal of Electromyography and Kinesiology, 10(2), 93101. https://doi.org/10.1016/S1050-6411(99)00028-0

Thelen, D. G., Wojcik, L. A., Schultz, A. B., Ashton-Miller, J. A., \& Alexander, N. B. (1997). Age differences in using a rapid step to regain balance during a forward fall. The 
Journals of Gerontology. Series A, Biological Sciences and Medical Sciences, 52(1),

M8-M13. https://doi.org/10.1093/gerona/52A.1.M8

Thorborg, K., Bandholm, T., \& Hölmich, P. (2013). Hip- and knee-strength assessments using a hand-held dynamometer with external belt-fixation are inter-tester reliable. Knee Surgery, Sports Traumatology, Arthroscopy, 21(3), 550-555. https://doi.org/10.1007/s00167-012-2115-2

Van Dieën, J. H., Pijnappels, M., \& Bobbert, M. F. (2005). Age-related intrinsic limitations in preventing a trip and regaining balance after a trip. Safety Science, 43(7), 437-453. https://doi.org/10.1016/j.ssci.2005.08.008

Wojcik, L. A., Thelen, D. G., Schultz, A. B., Ashton-Miller, J. A., \& Alexander, N. B. (1999). Age and Gender differences in single step recovery from a forward fall. Journal of Gerontology, 54(I), 44-50. https://doi.org/10.1093/gerona/54.1.M44

Wojcik, L. A., Thelen, D. G., Schultz, A. B., Ashton-Miller, J. A., \& Alexander, N. B. (2001). Age and gender differences in peak lower extremity joint torques and ranges of motion used during single-step balance recovery from a forward fall. Journal of Biomechanics, 34(1), 67-73. https://doi.org/10.1016/S0021-9290(00)00152-4 
Figure 1.
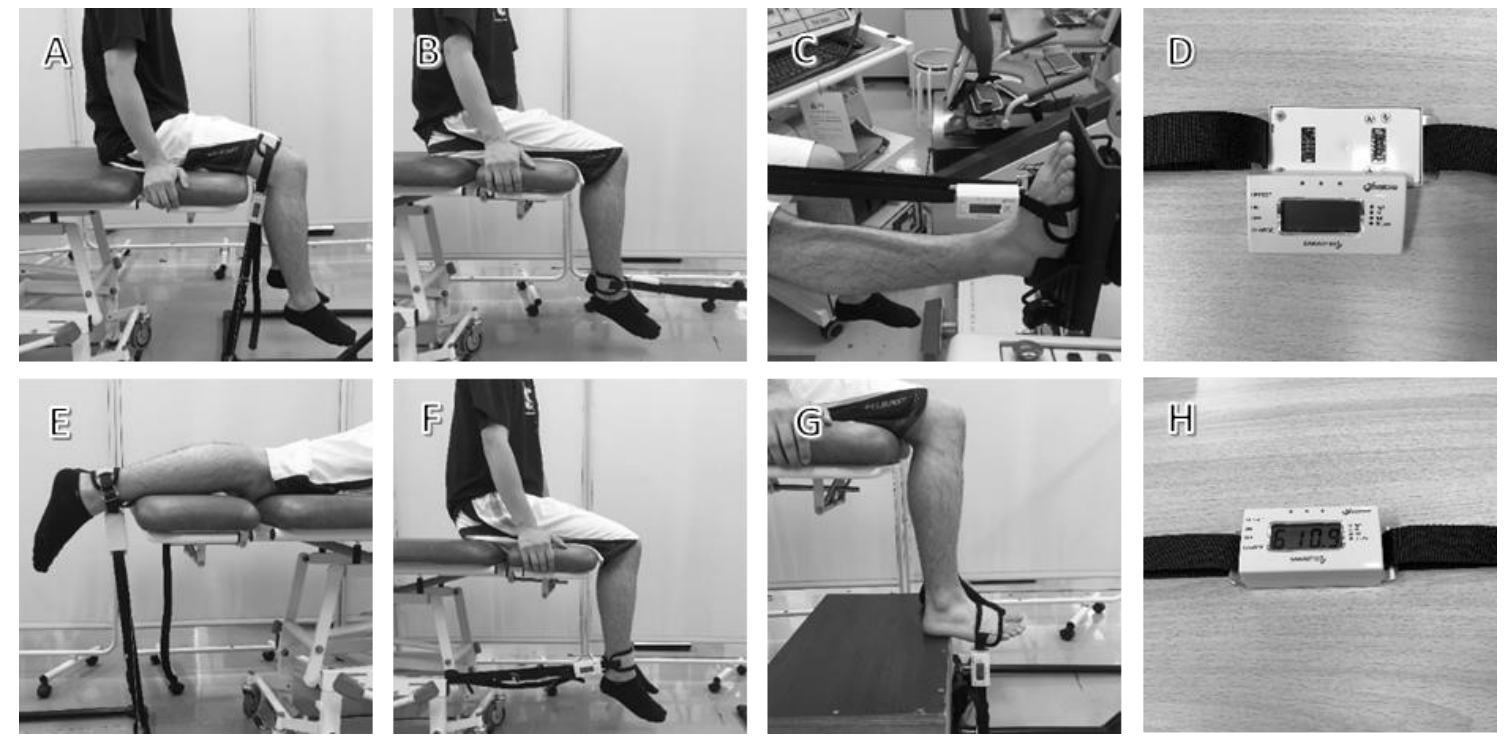
Figure title and caption

Figure 1: Testing positions for force measurements for the dynamometer and belt with pull sensor.

The belt with the pull sensor was fixed to the metal base frame placed on the floor for hip flexion (A), hip extension (E), and ankle dorsiflexion (G). The belt was also externally fixed to the vertical metal bar or a plinth frame for knee flexion $(B)$ or knee extension $(F)$, respectively. For the measurements of ankle plantar flexion force (C), the belt with pull sensor was fixed to the seat frame of the isokinetic joint torque measuring device to be straight along the long axis of the lower leg. The belt with the pull sensor and hand-held dynamometry (D), and the device in action $(\mathrm{H})$. 
Table 1

Table 1. Intra-class correlation coefficients for the maximum joint torques and rate of torque development at each time point.

\begin{tabular}{lcccccc}
\hline & Peak torque & RTD $_{0-50}$ & RTD $_{0-100}$ & RTD $_{0-150}$ & RTD $_{0-200}$ \\
\hline HF & $0.90(0.85-0.94)$ & $0.81(0.71-0.89)$ & $0.83(0.73-0.89)$ & $0.86(0.79-0.92)$ & $0.86(0.78-0.91)$ & $0.87(0.79-0.92)$ \\
HE & $0.95(0.92-0.97)$ & $0.77(0.64-0.86)$ & $0.82(0.73-0.89)$ & $0.83(0.74-0.90)$ & $0.92(0.87-0.95)$ & $0.87(0.80-0.92)$ \\
KF & $0.96(0.94-0.98)$ & $0.82(0.71-0.89)$ & $0.86(0.78-0.91)$ & $0.83(0.74-0.90)$ & $0.94(0.90-0.96)$ & $0.93(0.89-0.96)$ \\
KE & $0.91(0.86-0.94)$ & $0.74(0.60-0.84)$ & $0.84(0.75-0.90)$ & $0.83(0.74-0.90)$ & $0.88(0.82-0.93)$ & $0.89(0.83-0.93)$ \\
APF & $0.90(0.85-0.94)$ & $0.74(0.59-0.84)$ & $0.82(0.72-0.89)$ & $0.81(0.70-0.88)$ & $0.81(0.71-0.88)$ & $0.87(0.79-0.92)$ \\
ADF & $0.92(0.87-0.95)$ & $0.73(0.57-0.83)$ & $0.82(0.73-0.89)$ & $0.87(0.80-0.92)$ & $0.93(0.89-0.96)$ & $0.90(0.84-0.94)$ \\
\hline
\end{tabular}

These data were shown in the ICCs (95\% confidence intervals from lower bound to upper bound).

$\mathrm{HF}$, hip flexion; HE, hip extension; KF, knee flexion; KE, knee extension; APF, ankle plantarflexion; ADF, ankle dorsiflexion. 
Table 2

Table 2. Mean lower limb maximum joint torques and rate of torque development at each time point (mean \pm standard deviation).

\begin{tabular}{lcccccc}
\hline & $\begin{array}{c}\text { Maximum } \\
\text { joint torque }\end{array}$ & RTD $_{0-50}$ & RTD $_{0-100}$ & RTD $_{0-150}$ & RTD $_{0-200}$ & RTD $_{0-250}$ \\
\hline $\mathrm{HF}$ & $1.46 \pm 0.29$ & $9.71 \pm 4.07$ & $8.92 \pm 3.14$ & $5.76 \pm 1.67$ & $5.66 \pm 1.24$ & $4.53 \pm 0.91$ \\
$\mathrm{HE}$ & $1.42 \pm 0.38$ & $10.09 \pm 4.43$ & $9.16 \pm 3.05$ & $5.80 \pm 1.65$ & $5.62 \pm 1.62$ & $4.38 \pm 1.14$ \\
$\mathrm{KF}$ & $1.42 \pm 0.41$ & $9.81 \pm 4.88$ & $8.75 \pm 3.32$ & $5.70 \pm 1.84$ & $5.49 \pm 1.64$ & $4.40 \pm 1.31$ \\
$\mathrm{KE}$ & $2.44 \pm 0.53$ & $16.66 \pm 6.62$ & $15.76 \pm 4.84$ & $10.17 \pm 2.63$ & $9.52 \pm 2.20$ & $7.55 \pm 1.70$ \\
$\mathrm{APF}$ & $1.04 \pm 0.19$ & $7.27 \pm 3.07$ & $6.48 \pm 2.18$ & $4.14 \pm 1.00$ & $4.04 \pm 0.73$ & $3.26 \pm 0.61$ \\
$\mathrm{ADF}$ & $0.49 \pm 0.15$ & $3.59 \pm 1.53$ & $3.25 \pm 1.26$ & $1.94 \pm 0.68$ & $1.89 \pm 0.58$ & $1.51 \pm 0.46$ \\
\hline
\end{tabular}

Each time point RTD was calculated at all time points starting from onset at every $50 \mathrm{~ms}$ interval. The unit for maximum joint torques were "Nm/kg", and RTDs were "Nm/kg/s". HF, hip flexion; HE, hip extension; KF, knee flexion; KE, knee extension; APF, ankle plantarflexion; ADF, ankle dorsiflexion. 
Table 3

Table 3. Coefficients of correlation based on a single variable linear correlation analysis between maximum joint torques and rate of torque development at each time point and maximum recoverable lean angle

\begin{tabular}{|c|c|c|c|c|c|c|c|}
\hline & & $\begin{array}{c}\text { Maximum } \\
\text { torque }\end{array}$ & $\mathrm{RTD}_{0-50}$ & $\mathrm{RTD}_{0-100}$ & $\mathrm{RTD}_{0-150}$ & $\mathrm{RTD}_{0-200}$ & $\mathrm{RTD}_{0-250}$ \\
\hline \multirow{2}{*}{$\mathrm{HF}$} & $\mathrm{r}$ & $0.561 * *$ & $0.587 * *$ & $0.635 * *$ & $0.560 * *$ & $0.510 * *$ & $0.473 * *$ \\
\hline & ES & 0.46 & 0.53 & 0.68 & 0.46 & 0.35 & 0.29 \\
\hline \multirow{2}{*}{$\mathrm{HE}$} & $\mathrm{r}$ & $0.301 *$ & 0.142 & $0.407 * *$ & $0.285 *$ & $0.329 *$ & $0.345 * *$ \\
\hline & $\mathrm{ES}$ & 0.10 & 0.02 & 0.20 & 0.09 & 0.12 & 0.14 \\
\hline \multirow{2}{*}{$\mathrm{KF}$} & $\mathrm{r}$ & $0.341 *$ & $0.540 * *$ & $0.543 * *$ & 0.197 & $0.307 *$ & $0.353 * *$ \\
\hline & ES & 0.13 & 0.41 & 0.42 & 0.04 & 0.10 & 0.14 \\
\hline \multirow{2}{*}{$\mathrm{KE}$} & $\mathrm{r}$ & 0.237 & 0.237 & 0.128 & 0.095 & 0.141 & 0.132 \\
\hline & ES & 0.06 & 0.06 & 0.02 & 0.01 & 0.02 & 0.02 \\
\hline \multirow{2}{*}{$\mathrm{APF}$} & $\mathrm{r}$ & $0.334 *$ & $0.428 * *$ & $0.516 * *$ & 0.220 & $0.331 *$ & $0.352 * *$ \\
\hline & ES & 0.13 & 0.22 & 0.36 & 0.05 & 0.12 & 0.14 \\
\hline \multirow{2}{*}{$\mathrm{ADF}$} & $\mathrm{r}$ & $0.538 * *$ & 0.160 & 0.157 & 0.252 & $0.381 * *$ & $0.401 * *$ \\
\hline & ES & 0.41 & 0.03 & 0.03 & 0.07 & 0.17 & 0.19 \\
\hline
\end{tabular}

A significant correlation was denoted by $*=p<0.05$, and $* *=p<0.01$

HF, hip flexion; HE, hip extension; KF, knee flexion; KE, knee extension; APF, ankle plantarflexion; ADF, ankle dorsiflexion; ES, effect size given by Cohen's f ${ }^{2}$ 
Table 4

Table 4. Result of multiple stepwise regression analysis for predicting maximum recoverable lean angle.

\begin{tabular}{|c|c|c|c|c|c|c|}
\hline Variable & $\mathrm{B}$ & $95 \% \mathrm{CI}$ & SE & Beta & $\mathrm{T}$ & $\mathrm{P}$ \\
\hline \multicolumn{7}{|c|}{ Model: $\mathrm{R}^{2}=0.589, \mathrm{~F}=27.27, \mathrm{p}<0.001$} \\
\hline HF RTD0-50 & 0.443 & $0.163-0.724$ & 0.140 & 0.353 & 3.172 & 0.003 \\
\hline KF RTD $0-100$ & 0.574 & $0.289-0.859$ & 0.142 & 0.373 & 4.046 & $<0.001$ \\
\hline HF RTD0-150 & 0.863 & $0.190-1.536$ & 0.336 & 0.282 & 2.572 & 0.013 \\
\hline
\end{tabular}

HF, hip flexion; KF, knee flexion; RTD, rate of torque development; B, unstandardized coefficients of B; 95\%CI, $95 \%$ confidence interval for B and lower bound to upper bound; SE, standard error; Beta, standardized coefficients of Beta; $T$, $t$ value; $P, p$ value 